\title{
Methodics in Regional Population Projections in Sweden
}

\author{
By LARS WIDÉN
}

National Central Bureau of Statistics

\section{Object in view}

The country is divided into 282 economic regions. A projection is to be made of the population in every such region at the end of the years $1970,1975,1980$ and 1985.

\section{The statistical material}

The following data provide a basis for the projection:

For the country: information on the population according to sex and age at the turn of the years; annual reports on deaths, by sex and year of birth, and annual reports on births, by sex and date of birth of the mother.

For each region: reports on the population, by sex and age, at the ends of the years 1960 and 1965: from and including 1961 annual reports on internal out-migration, and in-migration, and annual reports on the net migration abroad according to sex and date of birth.

For each county: for the years $1950 / 51,1960 / 61$ and $1965 / 66$, indexes of the age-specific mortality and fertility.

\section{Method}

The initial value for the projections is constituted by information on the population, according to sex and five-year age groups in separate regions at the end of 1965 . This simultaneously involves a division of the population by five-year birth cohorts.

The principle for the population projections has been that, in respect of each region, a study is made of five-year birth cohorts according to sex from the end of 1965 until the end of 1970 , from the end of 1970 until the end of 1975 , and so on. This method requires that the change factors of the population are of cohort-period type. 


\section{Change factors of the population}

\subsection{Probability of dying}

The number of persons at the age of $x / x+4$ at the end of a calendar year $t$ is denoted by $\mathrm{P}_{x / x+4}$. They were accordingly born during the period $\mathrm{t}-(\mathrm{x}+4) / \mathrm{t}-\mathrm{x}$.

The probability that a person born during the period $t-(x+4) / t-x$ will die during the period $t+1 / t+5$, is thus defined by:

$q_{x / x+4}=\frac{t-(x+4) / t-x D^{t+1 / t+5}}{P_{x / x+4}^{t}}$

in which the numerator indicates the number of deaths within the cohort $t-(x+4) / t-x$ during the period $t+1 / t+5$. This risk of dying is accordingly of cohort-period type.

For those born during the period $t+1 / t+5$, the risk of dying during the same period will be:

$q_{b}=\frac{t+1 / t+5 D^{t+1 / t+5}}{B^{t+1 / t+5}}$

in which the numerator indicates the number of births during the period $\mathrm{t}+1 / \mathrm{t}+\mathbf{5}$.

The risks of dying of this cohort-period type have been calculated for the whole country for separate five-year periods. For each five-year age group, the risks observed for the latest periods have been plotted in a semilogarithmic diagram. The points arrived at by this means have been adopted as a basis for graduation and extrapolation. Extrapolation has been effected by a graphic method with straight lines, which consequently implies that the risks projected are subsequently developed in geometrical progression.

Mortality in Sweden exhibits regional variations. Thus the mortality of men between the ages of 45 and 64 is approximately 30 per cent higher in Stockholm than in the country as a whole. Notwithstanding this higher mortality in Stockholm, it has been assumed in the population projections that the mortality in all regions is the same as that in the whole country.

\subsection{Internal out-migration risks and in-migration proportions}

The cohort observed at a turn of the year is subject to the risk of certain demographic events during an approaching period. Consequently, one can speak of the risk of out-migration, but not of the risk of inmigration, since those in-migrating are not included in the risk volume used here.

Let us denote a certain region by (i).

The probability of out-migration from region (i) is: 
o (i) $)_{x / x+4}=\frac{t-(x+4) / t-x_{0(i)} t+1 / t+5}{P(i)^{t}}$

in which the numerator indicates the number of out-migration from region (i) within the cohort $t-(x+4) / t-x$ during the period $t+1 / t+5$, and the denominator the number in this cohort at the end of calendar year $t$.

For those born during the period $t+1 / t+5$, the risk of out-migration is:

$O(i)_{b}=\frac{t+1 / t+5 O(i)^{t+1 / t+5}}{B(i)^{t+1 / t+5}}$,

in which $\mathrm{B}(\mathrm{i})^{t+1 / t+5}$ denotes the number born in region (i) during the period $t+1 / t+5$.

The total of those migrating from all regions of the cohort $t-(x+4 /$ $t-x$ during the period $t+1 / t+5$ becomes:

$$
\sum_{i=1}^{282} \mathrm{t}-(\mathrm{x}+4) / \mathrm{t}-\mathrm{x} O(\mathrm{i})^{\mathrm{t}+1 / \mathrm{t}+5}=\mathrm{t}-(\mathrm{x}+4) / \mathrm{t}-\mathrm{x} \mathrm{O}^{\mathrm{t}+1 / \mathrm{t}+5}
$$

The in-migration proportion for region (i) is:

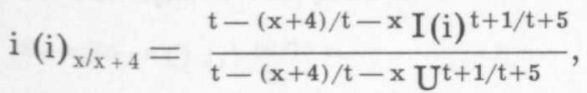

in which the numerator indicates the number of in-migrants into region (i) within cohort $t-(x+4) / t-x$ during the period $t+1 / t+5$ and the denominator the number out-migrating from all regions of this cohort during the same period.

For those born during the period $t+1 / t+5$, the in-migration proportion becomes:

$i(i)_{b}=\frac{t+1 / t+5 I(i){ }^{t+1 / t+5}}{t+1 / t+5 O^{t+1 / t+5}}$

In general, the following applies: $\sum_{\mathrm{i}=1}^{282} \mathrm{i}(\mathrm{i})_{\mathrm{x} / \mathrm{x}+4=1}$

Statistics of internal migrations, by regions, and according to sex and year of birth, are available only for the period of five years 1961-65. This period coincides with a stage of pronounced prosperity. As a foundation for a calculation of population it would have been valuable to have had access to migration statistics which cover the entire trade cycle. It is probable that the pattern of migration varies with trade conditions in a rather marked way.

For lack of more complete statistics, the basis for the projection has been constituted by the out-migration risks and in-migration proportions for the period $1961-65$. 


\subsection{Fertility rates}

As a measure of fertility, use has been made of equations of the type: $f_{x / x+4}=\frac{t-(x+4) / t-x B^{t+1 / t+5}}{1 / 2\left[P_{x / x+4}^{t}+P_{x+5 / x+9}^{t+5}\right]}$ in which the numerator indicates, for the period $t+1 / t+5$, the number of live births to mothers within the cohort $t-(x+4) / t-x$, and the denominator those from the same cohort during the period in respect of the time lived through.

Fertility rates of the above type have been calculated for the entire country for different periods. These rates have been compiled by cohort and by period. The analysis has been aimed at the discovery of trends or other stable patterns which can be used for extrapolation of the rates. The results obtained from this analysis indicated that fertility during the last decade has been almost constant, and that it can be expected that this development will continue. Although the fertility displays some regional variations, in population calculations it has been assumed that there will be the same fertility in all regions.

\section{The demographic model}

\subsection{Assumptions}

The following data are given:

The country is divided into 282 regions. A certain region is denoted by (i).

The observed population in each region, according to sex and age, at the end of 1965 , was $P$ (i) ${ }_{x}^{65} / x+4$

Period of calculation: $1966-70$

Projected values of:

probability of dying: $\mathrm{q}_{\mathrm{x} / \mathrm{x}+4}$

risks of out-migration: $o(i)_{x / x+4}$

in-migration proportions: $i(i)_{x / x+4}$

net immigration: $N(\text { i })_{x / x+4}$

fertility rates: $f_{x / x+4}$

proportion of boys in the birth cohort: a

It has been assumed that the net immigration in the country amounts to 50,000 during a five-year period.

\subsection{Calculation of the number surviving in a stated region}

The general formula for forecasting the population of a region (i) until the end of the year 1970 can be written: 


$$
\begin{aligned}
& \mathrm{P} \text { (i) }{ }_{\mathrm{x}+5 / \mathrm{x}+9}^{70}=\mathrm{P} \text { (i) }{ }_{\mathrm{x} / \mathrm{x}+4}^{65}-{ }^{61-\mathrm{x} / 65-\mathrm{x}} \mathrm{D} \text { (i) }{ }^{66 / 70}-{ }^{61-\mathrm{x} / 65-\mathrm{x}} \mathrm{O} \text { (i) }{ }^{66 / 70} \\
& +{ }^{61-\mathrm{x} / 65-\mathrm{x}} \mathrm{I} \text { (i) }{ }^{66 / 70}+{ }^{61-\mathrm{x} / 65-\mathrm{x}} \mathrm{N} \text { (i) }{ }^{66 / 70},
\end{aligned}
$$

in which D (i) denotes the number of deaths, $\mathrm{O}$ (i) the number of internal out-migrants, I (i) the number of internal in-migrants, and $\mathrm{N}$ (i) the number of net immigrants in the cohort $61-\mathrm{x} / 65-\mathrm{x}$, where $\mathrm{x}$ assumes the values $0,5,10$, and so on.

For the time being, the internal in-migrants and net immigrants will be disregarded.

The observed population $\mathrm{P}(\mathrm{i})_{\mathrm{x} / \mathrm{x}+4}^{65}$, during the period $66 / 70$, is exposed to two risks, to a great extent mutually independent: these are the probability of dying, and the probability of out-migration. On the assumption that only these risks influence the population, there is derived the following expression for those who survive at the end of the period, and have not migrated from the region:

$\mathrm{P}(\mathrm{i})^{70}{ }_{\mathrm{x}+5 / \mathrm{x}+9}=$

$$
\left[1-\mathrm{q}_{\mathrm{x} / \mathrm{x}+4}\right] \cdot\left[1-\mathrm{O}(\mathrm{i})_{\mathrm{x} / \mathrm{x}+4}\right] \cdot \mathrm{P}(\mathrm{i})^{65}{ }_{\mathrm{x} / \mathrm{x}+4}
$$

At the end of the period, those surviving of out-migrants will be:

$61-\mathrm{x} / 65-\mathrm{x} O(\mathrm{i}){ }^{66 / 70}=$

$$
\left[1-q_{x / x+4}\right] \cdot o(i)_{x / x+4} \cdot P(i)^{65}{ }_{x / x+4}
$$

When the number of surviving out-migrants has been calculated for all regions, their total figures are added cohort by cohort. For the cohort $61-\mathrm{x} / 65-\mathrm{x}$, the total out-migration of survivors at the end of the period of calculation becomes:

$$
61-\mathrm{x} / 65-\mathrm{x} O \quad 66 / 70=\sum_{i=1}^{282} \sum^{61-x / 65-x} \mathrm{O} \text { (i) } 66 / 70
$$

The next step in the calculation takes the form of dividing the total number of surviving out-migrants of a certain cohort in distinct regions in the form of in-migrants. This has been done with the guidance of the in-migration proportions. Accordingly, the number of in-migrants in the cohort $61-\mathrm{x} / 65-\mathrm{x}$ to region (i) becomes:

$$
61-x / 65-x I(i){ }^{66 / 70}=i(i) x / x+4 \quad 61-x / 65-x O \quad 66 / 70
$$

The general formula stated above for calculation of the population in a given region can now be written:

$$
\begin{aligned}
& \mathrm{P}(\mathrm{i})^{70}{ }_{\mathrm{x}+5 / \mathrm{x}+9}= \\
& {\left[1-\mathrm{q}_{\mathrm{x} / \mathrm{x}+4}\right] \cdot\left[1-0(i)_{\mathrm{x} / \mathrm{x}+4}\right] \cdot \mathrm{P}(\mathrm{i})^{65}{ }_{\mathrm{x} / \mathrm{x}+4}+\mathrm{i}(\mathrm{i})_{\mathrm{x} / \mathrm{x}+4} \cdot{ }^{61-\mathrm{x} / 65-\mathrm{x}} \mathrm{O} 66 / 70} \\
& +{ }^{61-\mathrm{x} / 65-\mathrm{x}} \mathrm{N}(\mathrm{i})^{66 / 70}
\end{aligned}
$$


5.3 Calculation of the size of the youngest age group in a stated region at the end of the forecasting period

For each region, the number of live births has been calculated by the formula:

$$
\mathrm{B}(\mathrm{i})^{66 / 70}=1 / 2 \sum_{10 / 14}^{45 / 49} \mathrm{f}_{\mathrm{x} / \mathrm{x}+4} \cdot\left[\mathrm{P}(\mathrm{i})^{65}{ }_{\mathrm{x} / \mathrm{x}+4}+\mathrm{P}(\mathrm{i})^{70}{ }_{\mathrm{x}+5 / \mathrm{x}+9}\right]
$$

The number of births has then been divided according to sex, and projected until the end of the year 1970 (the symbol for sex has not been indicated in the formulae given below)

Number of boys

$$
\begin{aligned}
& \mathrm{P}(\mathrm{i})^{70}{ }_{0-4}=\mathrm{a} \cdot\left[1-\mathrm{q}_{\mathrm{b}}\right] \cdot\left[1-\mathrm{O}(\mathrm{i})_{\mathrm{b}}\right] \cdot \mathrm{B}(\mathrm{i})^{66 / 70} \\
& +\mathrm{i} \mathrm{(i)})_{\mathrm{b}} \cdot{ }^{66 / 70} \mathrm{O}^{66 / 70}+{ }^{66 / 70} \mathrm{~N}(\mathrm{i})^{66 / 70}
\end{aligned}
$$

Number of girls

$$
\begin{aligned}
& \mathrm{P}(\mathrm{i})^{70}{ }_{0-4}=[1-\mathrm{a}] \cdot\left[1-\mathrm{q}_{\mathrm{b}}\right] \cdot\left[1-\mathrm{o}(\mathrm{u})_{\mathrm{b}}\right] \cdot \mathrm{B}(\mathrm{i})^{66 / 70} \\
& +\mathrm{i}(\mathrm{i})_{\mathrm{b}} \cdot{ }^{66 / 70} \mathrm{O}^{66 / 70}+{ }^{66 / 70} \mathrm{~N}(\mathrm{i})^{66 / 70}
\end{aligned}
$$

\section{Discussion:}

The ensuing discussion had the following speakers: Forsberg, Fougstedt, Hoem, Hofsten, Hägerstrand, Karlsson, Matthiessen, Narvi and Quensel.

Most of the speakers dealt with the questions of which purposes should be fulfilled by the forecasts, and which weaknesses are attached to the current methods of forecasting. Among the points established was one that the forecasts had exercised a reorganising influence upon regional planning, but that they also - for good or bad - determine the development. They have, for instance, given the frame values within which planning must be effected. Frame values are needed in national forecasts, forecasts for provinces and major regions. A more doubtful attitude was adopted in regard to the significance of forecasts for communal planning. It was considered that the communes themselves should have the opportunity of determining the development. In making forecasts for small areas, it is frequently necessary to establish contact with the local authorities, and not to rely solely upon components which had been used earlier.

The importance attached to paying regard to real-economic factors was pointed out from different quarters. Many speakers referred to the assumptions used in working on the forecasts. More attention must be paid to the stability of the components upon which forecasts are built. It was stated further that in many instances irrelevant data are employed. A start is made from constant fertility, and so on, despite the fact that a change is to be expected in the future. One question mark was established as the future mean number of children, and the effects this will have if it is reached at an earlier age than now. The effect exerted by P-pills upon fertility also comes into the future. The importance of analysis of stability of the components used in the forecasts was emphasised. 